\title{
Augmented Reality sebagai Alat Pengenalan Hewan Purbakala dengan Animasi 3D menggunakan Metode Single Marker
}

\author{
Meyti Eka Apriyani ${ }^{1}$, Robie Gustianto ${ }^{2}$ \\ ${ }^{1,2}$ Jurusan Teknik Multimedia dan Jaringan, Politeknik Negeri Batam \\ ${ }^{1,2}$ Parkway Batam Centre 29461 \\ ${ }^{1}$ meyti24@gmail.com, ${ }^{2}$ robie.gustianto8@gmail.com
}

\begin{abstract}
Abstrak - Saat ini untuk mempelajari hewan purbakala melalui pelajaran sejarah di sekolah hanya dilakukan hanya melalui sebuah buku dan gambar yang terdapat pada buku-buku dan alat peraga biasa, tetapi dengan menggunakan teknologi augmented reality diharapkan dalam pembelajarannya dapat membuat pelajaran sejarah terutama mengenai hewan purbakala dapat lebih menarik dan menyenangkan karena augmented reality dapat menjadi sebuah alat peraga virtualisasi hewan purbakala dlam bentuk 3D. Aplikasi augmented reality ini sebagai media pengenalan hewan purbakala kepada anak-anak usia 13 sampai 18 tahun secara virtual menggunakan perangkat smartphone agar proses pengenalan Hewan purbakala dapat menjadi lebih menarik dan mudah diapliaksikan karena mudah dibawa serta tidak menggunakan alat peraga yang sulit didapat dan memiliki harga yang mahal. Virtualisasi Alat Peraga Pengenalan Hewan Purbakala menggunakan augmented reality dapat menampilkan Animasi Hewan purbakala dalam bentuk 3D. Dengan proses, pengguna menjalankan aplikasi kemudian aplikasi akan melakukan pelacakan marker, setelah marker dikenali sesuai data acuan yang terdapat didalam sistem aplikasi, maka aplikasi dapat menampilkan binatang Purbakala secara 3D pada layar smartphone.
\end{abstract}

Kata kunci - Augmented Reality, Virtualisasi, Hewan Purbakala, Smartphone.

Abstract - This time to learn Animals Archaeological through history lesson at school only be done only through a book and images contained in the books and props usual, but by using augmented reality technology is expected to be able to make learning the lessons of history, especially about extinct animals can be more attractive and fun for augmented reality can be a props virtualization extinct animals in the development of 3D shapes. Augmented Reality application is a media introduction of extinct animals to children aged 13 to 18 years virtually using a smartphone device to allow the introduction of ancient Animals can become more attractive and easier diapliaksikan because of their portability and do not use props are hard to come by and have a price expensive. Virtualization Introduction Viewer Tool Animals - Animals Antiquities using Augmented reality can show ancient Animals Animation in 3D. With the process, the user running the application and then the application will do the tracking marker, after the marker recognized by the appropriate reference data contained in the application system, the application can display Antiquities animals in 3D on a smartphone screen.

Keywords: Augmented Reality, Virtualization, Animals Archaeology, Smartphone.

\section{PENDAHULUAN}

Realitas maya adalah teknologi yang membuat pengguna dapat berinteraksi dengan suatu lingkungan yang disimulasikan oleh komputer (computersimulated environment), suatu lingkungan sebenarnya yang ditiru atau $r$ suatu lingkungan baru yang terdapat dalam komputer. Dalam virtual reality, informasi mengenai dunia virtual yang ditampilkan ke indra pengguna dapat bersifat visual (paling umum) menggunakan layar atau head mounted display, audio menggunakan headphone, kontroler, dan bahkan sentuhan menggunakan sarung tangan khusus.

Namun, pada perkembangannya virtual reality memiliki cabang baru yang bahkan menyaingi virtual reality itu sendiri. Teknologi tersebut bernama Augmented Reality (sering disingkat menjadi AR).
Prinsipnya secara umum masih sama dengan virtual reality, yaitu bersifat, interaktif, immersion (membenamkan/memasukkan), realtime, dan objek virtual biasanya berbentuk 3 dimensi. Kebalikan dari virtual reality yang menggabungkan objek nyata (user) kedalam lingkungan virtual, augmented reality menggabungkan objek virtual pada lingkungan nyata. Kelebihan utama dari augmented reality dibandingkan virtual reality adalah pengembangannya yang lebih mudah dan murah. Kelebihan lain dari augmented reality yaitu dapat diimplementasikan secara luas dalam berbagai media. Sebagai aplikasi dalam sebuah smartphone, dalam bingkisan sebuah produk, bahkan media cetak seperti buku, majalah atau koran.

Saat ini untuk belajar mengenai hewan purbakala ketika belajar sejarah di sekolah setingkat SMP dan 
SMA hanya dapat dipelajari dari buku sejarah saja, dimana hanya terdapat gambar berupa gambar fosil hewan purbakala yang ditemukan di beberapa tempat didunia tanpa diketahui bagaimana cara hewan tersebut berjalan, berlari, makan, atau bahkan ketika mereka mati. Tapi kini dengan adanya teknologi augmented reality ini dapat dibuat bentuk virtual animasi 3D hewan purbakala berdasarkan masingmasing fosil.

Dengan kelebihannya tersebut, augmented reality memiliki banyak peluang untuk terus dikembangkan, tidak ketinggalan dalam bidang pendidikan sebagai media pembelajaran. Media pembelajaran yang dimaksud adalah media yang dapat menimbulkan rasa ketertarikan siswa untuk terfokus pada pembelajaran dan merangsang peran aktif siswa dalam menemukan, mengkonstruksi pengetahuannya sendiri dalam proses pembelajaran. Dan diharapkan dengan dibuatnya media pembelajaran berbasis augmented reality ini, proses pembelajaran dapat terlaksana dengan baik tanpa terhambat oleh terbatasnya alat peraga atau peralatan praktikum.

\section{A. Pengertian Hewan purbakala}

Hewan purbakala adalah hewan yang hidup pada masa lampau dan sekarang telah punah. Biasanya hewan-hewan ini hanya dikenali dari sisa-sisa tulang belulangnya yang disebut fosil. Ada jenis hewan purbakala dianggap telah punah, tetapi ternyata ditemukan masih hidup, maka hewan ini disebut fosil hidup, seperti ikan coelacanth. Hewan Purbakala yang digunakan pada penelitian ini adalah berasal dari jenis dinosaurus [14].

\section{B. Augmented Reality}

Teknologi augmented reality merupakan salah satu trobosan yang digunakan akhir-akhir ini di bidang interaksi. Penggunaan teknologi ini akan sangat membantu dalam menyampaikan informasi kepada pengguna. Augmented Reality merupakan teknologi interaksi yang menggabungkan dunia nyata dan dunia maya.

Dalam teknologi augmented reality ada tiga karakteristik yang menjadi dasar diantaranya adalah kombinasi pada dunia nyata dan virtual, interaksi yang berjalan secara real-time, dan karakteristik terakhir adalah bentuk obyek yang berupa 3 dimensi atau 3D. Bentuk data kontekstual dalam augmented reality ini dapat berupa data lokasi, audio, video ataupun dalam bentuk model dan animasi 3D.

Pada umumnya komponen yang yang diperlukan dalam pembuatan augmented reality ini adalah:
1. Komputer
2. Marker
3. Kamera

\section{Single Marker}

Single marker atau yang dikenal sebagai satu penanda dalam augmented reality. Satu penanda dalam mendeteksi gambar yang dijadikan sebagai media marker dan hanya satu objek saja yang keluar, berbeda dengan multi marker yang dapat mendeteksi gambar yang dijadikan sebagai media marker dan banyak objek yang dapat keluar dalam satu waktu mendeteksi marker [5].

\section{Vuforia Qualcom}

Vuforia adalah augmented reality Software Development untuk perangkat bergerak yang memudahkan pembuatan aplikasi augmented reality. Vuforia menggunakan teknologi Computer Vision untuk mengenali dan melacak marker atau image target dan objek 3D sederhana, seperti kotak, secara real-time.

\section{METODOLOGI PENELITIAN}

Metodologi penelitian dalam pembuatan aplikasi augmented reality ini cara kerja sistem secara garis besar yaitu berupa pembuatan arsitektur sistem, script program, model 3D dan aplikasi android. Secara umum Deskripsi sistem adalah sebagai berikut.

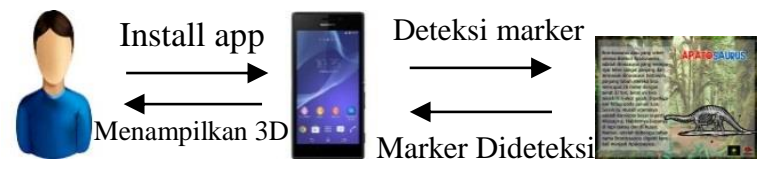

Gambar 1. Deskripsi Umum Sistem

Pada Gambar 1 dapat diketahui Secara umum deskripsi sistem adalah :

1. Sistem dapat mendeteksi marker dan marker dapat dideteksi.

2. Sistem dapat menentukan posisi objek 3D diatas marker.

3. Sistem dapat mengeluarkan posisi objek 3D dan suara.

Aplikasi augmented reality ini dibangun dengan menggunakan Unity 4 dimana aplikasi ini adalah salah satu software mendukung untuk pembuatan augmented reality dan sudah mendukung library Vuforia (database image target) yang sudah terintegrasi dengan berbagai jenis platform. Proses perancangan meliputi .

1. Membuat marker pada setiap objek.

2. Membuat 3D object dan animasi serta menambahkan fitur suara.

Perancangan penelitian ini dimulai dengan membuat sebuah diagram use case. Use case ini merupakan gambaran dari fungsionalitas yang diterapkan ke dalam sistem. Use case dapat diketahui dari bagaimana interaksi antara actor dengan sistem. 
Berikut ini adalah gambaran use case diagram.

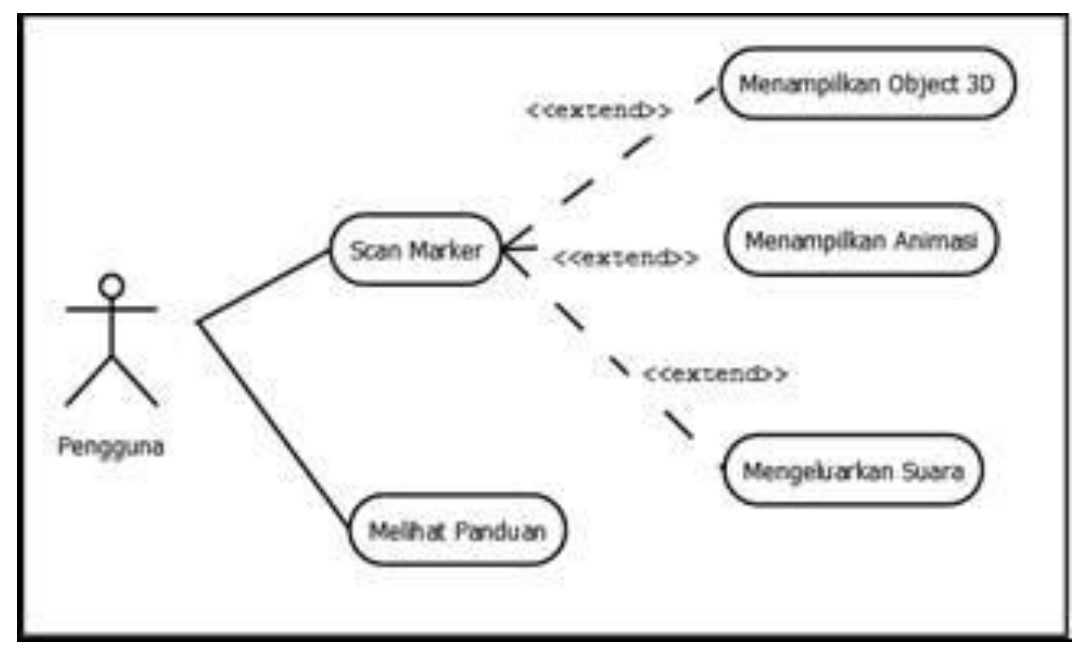

Gambar 2. Use Case Diagram

Use case terdiri dari aktor yaitu pengguna. Pengguna dapat melakukan fungsi scan marker dan melihat panduan.

Tyrannosaurus Rex atau T-rex adalah dinosaurus terpopuler didunia karena bentuknya yang seram, besar,dan giginya yang tajam dinosaurus ini seringkali banyak digunakan di film sebagai monster. Desain karakter untuk hewan purbakala T-rex merupakan desain yang dibuat untuk dijadikan desain karakter 3D.

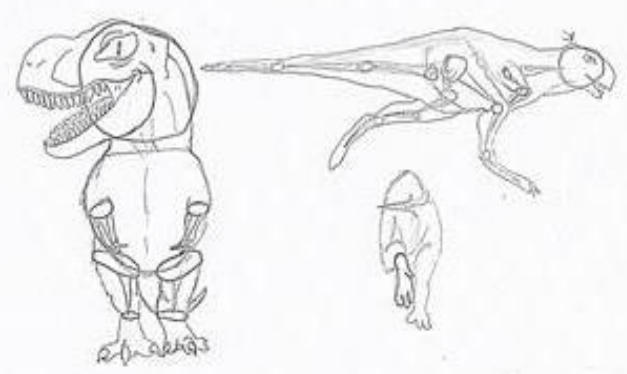

Gambar 3. Sketsa Karakter 3D T-rex

Kemudian desain 3D object dan animasi dibuat dengan menggunakan software Maya dan kemudian di animasikan. Berikut ini contoh gambar desain 3D T-rex.
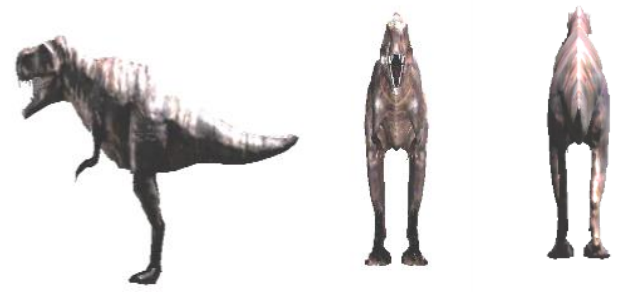

Gambar 4. Desain 3D T-rex

Selain sketsa desain karakter hal yang diperlukan adalah marker. Desain marker dibuat untuk membantu berjalannya aplikasi ini. Karena menggunakan single marker maka setiap object 3D memiliki marker sendiri. Berikut ini desain marker untuk setiap desain 3D.

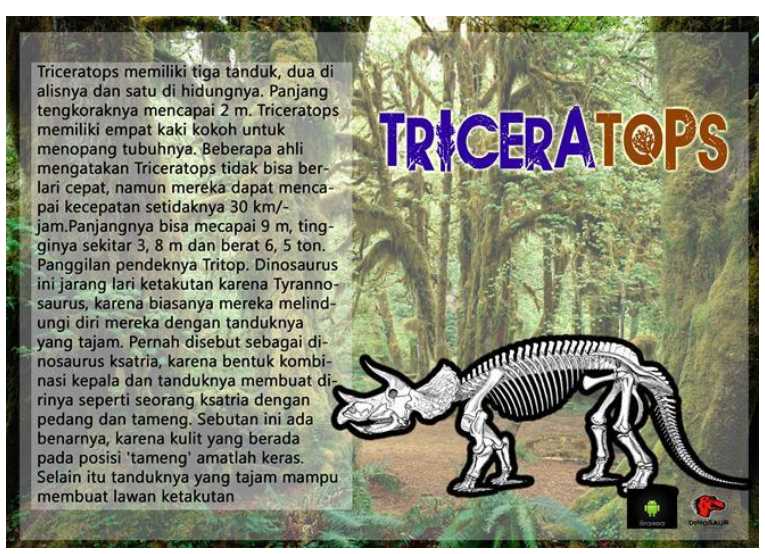

Gambar 5 Desain 3D T-rex

\section{HASIL DAN PEMBAHASAN}

Hasil penelitian berupa objek 3D, Animasi 3D dan pembuatan Augmented Reality.

\section{A. Konsep 3D}

Konsep 3D pada penelitian ini menggunakan metode augmented reality berbasis android [13]yang sebelumnya adalah merupakan Objek 3D yang diam kemudian di kembangkan dengan menambahkan animasi 3D.

\section{B. Pembuatan objek $3 D$}

Pada bagian ini akan dibuat objek 3D dinosaurus menggunakan aplikasi maya. Pertama dibuat dari cube dengan jumlah sisinya 20 X 20 kemudian di bentuk sesuai dengan pola gambar sketsa yang sudah di buat. 
Augmented Reality sebagai Alat Pengenalan Hewan Purbakala dengan Animasi 3D menggunakan Metode Single Marker
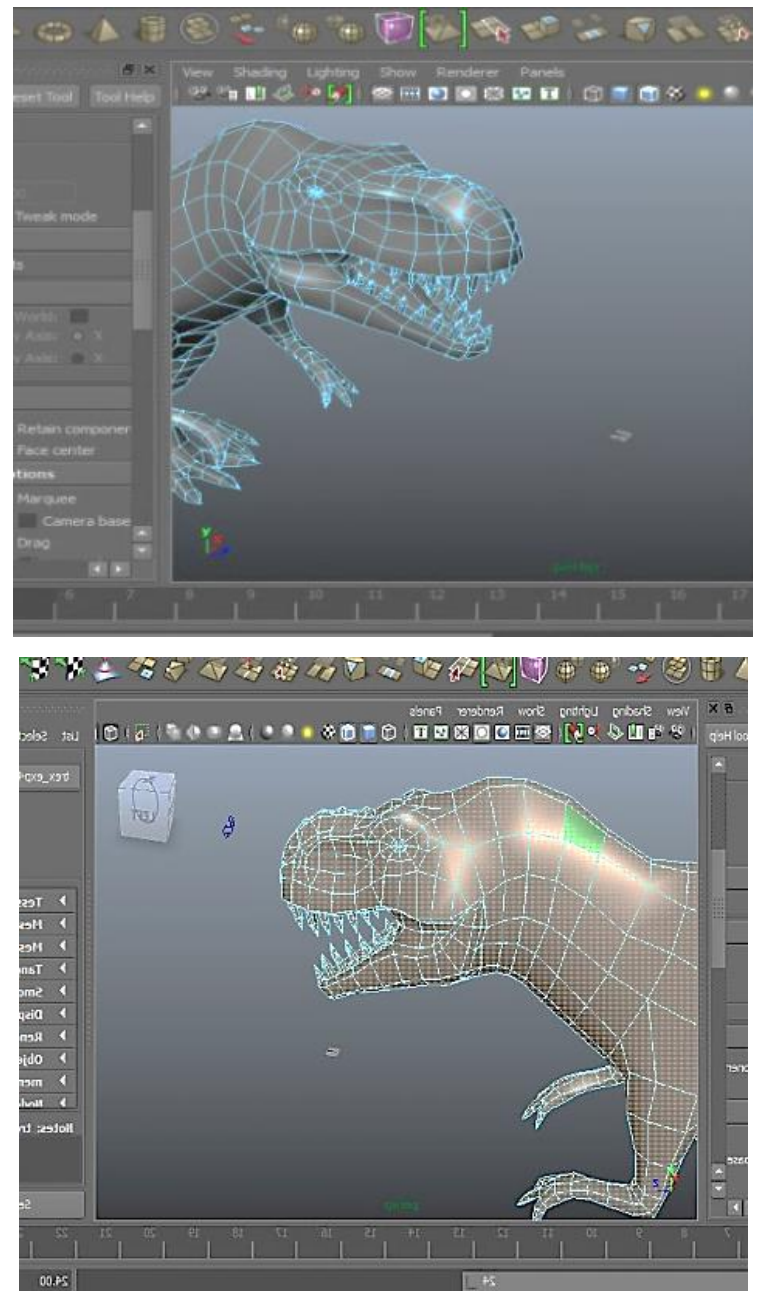

Gambar 6. Pembuatan Objek Bagian Depan T-rex

\section{Rigging}

Proses Rigging adalah proses pembentukan rangka untuk objek 3D agar dapat di animasikan atau di gerakkan.

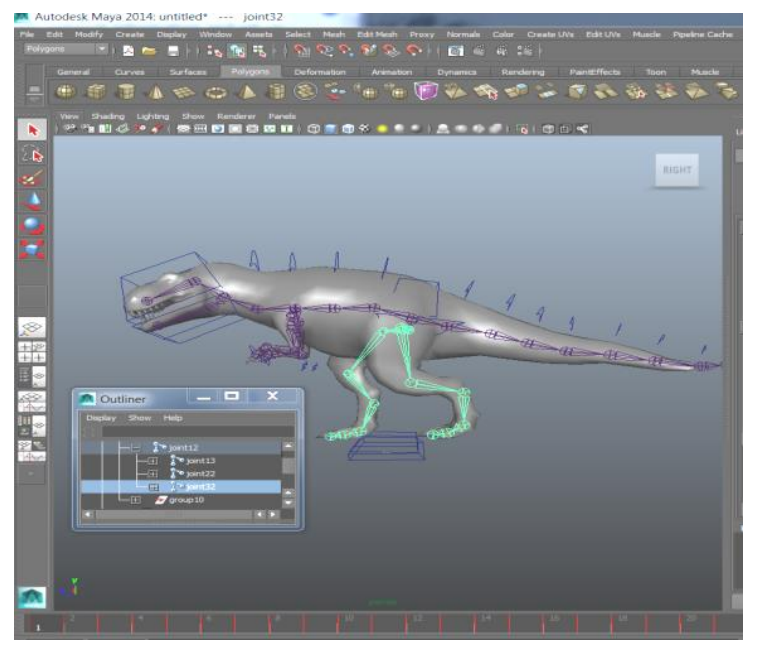

Gambar 7. Rigging T-rex

\section{Animate}

Animate adalah proses menggerakan objek 3D pada sebuah aplikasi, setelah rigging selesai maka animate atau animasi dapat dilakukan dengan mudah karena hanya menggerakan tulang - tulang rigging yang ada, cara animating pada umumnya adalah sama yaitu memilih rigg atau tulang yang akan di gerakkan, kemudian pilih frame keberapa gerakan itu akan dilakukan, dan gerakkan rih yang sudah dipilih menggunakan tools seperti Rotate dan move.

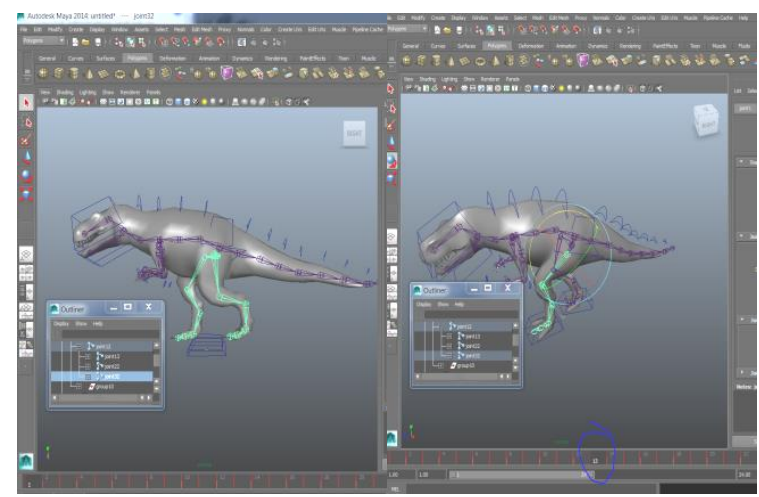

Gambar 8. Animate T-rex

Gambar 8 adalah gambar animate dari T-rex perubahan terlihat dari gambar frame 1 kemudian kaki bergerak pada frame 13 .

\section{E. Pembuatan Augmented Reality}

Setelah selesai file di unduh kemudian buka program unity. Selanjutnya import dataset atau marker ke dalam unity, setelah selesai import pada aplikasi Unity, kemudian masuk kedalam file prefabs, pilih Arcamera dan Imagetarget kedalam Hierarchy.

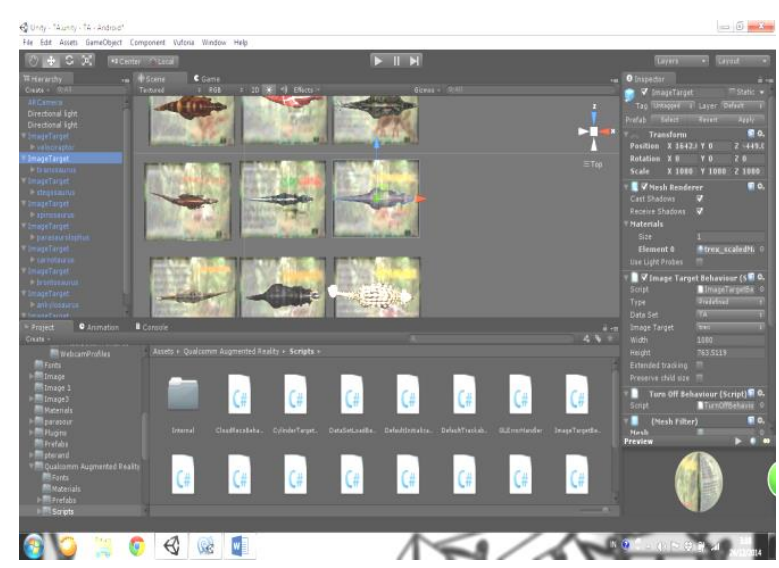

Gambar 9. MemasukkanKkarakter 3D ke dalam ImageTarget

\section{PEMBAHASAN}

Pada proses pembuatan aplikasi ini tidak memerlukan pemilihan audio atau file 3D tertentu karena pada software Unity tempat pembuatan aplikasi ini sudah mendukung banyak format file audio dan $3 \mathrm{D}$, tetapi pada aplikasi ini menggunakan format audio .mp3 dan format 3D .fbx. Penggunaan kamera pada aplikasi juga hanya dapat digunakan pada tipe kamera smartphone yang sudah memiliki fitur auto fokus 
minimum memiliki resolusi 2 megapixel. Augmented reality yang dibuat ini menggunakan metode single marker dimana hanya dapat melakukan Scaning 1 Marker saja tidak dapat 2 marker sekaligus. Setelah Aplikasi ini sudah berhasil dibuat selanjutnya adalah pengujian menggunakan smartphone.

\section{A. Hasil Uji Coba Pada Smartphone}

Pada tahap ini adalah tahap uji coba pada smartphone untuk memastikan aplikasi dapat berjalan sesuai keinginan atau tidak. Setelah berhasil menginstall aplikasi kemudian buka aplikasi untuk melihat tampilan GUI menu.

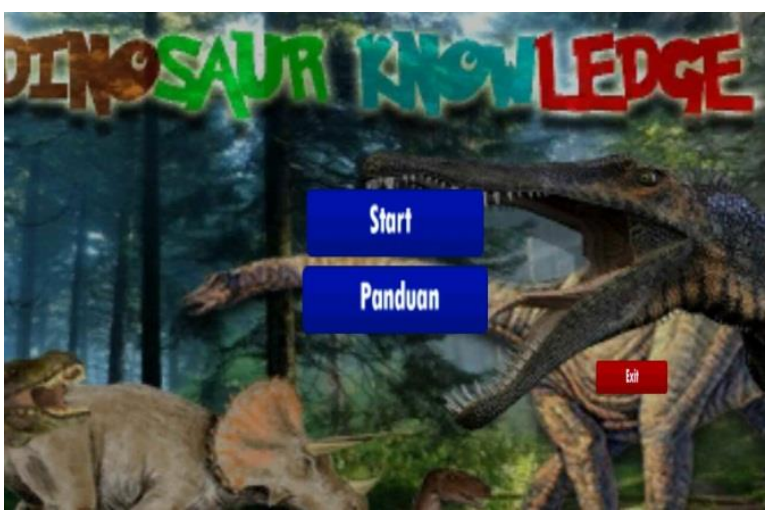

Gambar 10. Tampilan Menu

Setelah tampil tampilan menu selanjutnya lakukan pengujian pada fungsi semua button apakah berfungsi sesuai tujuan masing masing.

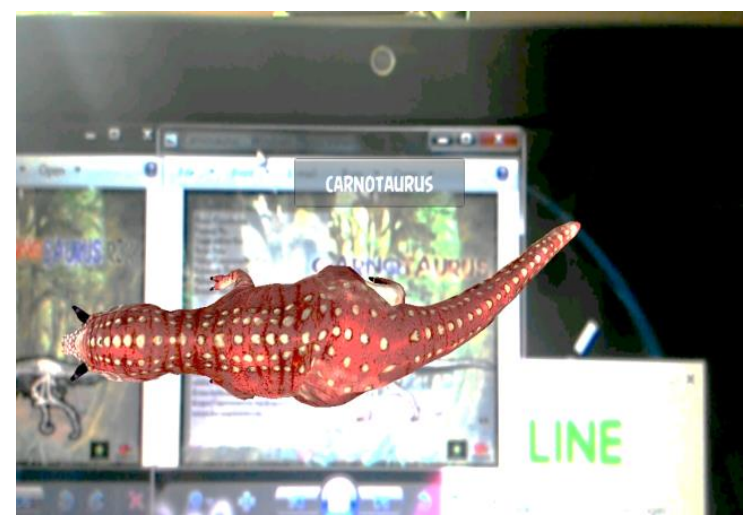

Gambar 11. Tampilan Objeck Setelah Scan Marker

Setelah semua fungsi berfungsi sesuai keinginan selanjutnya adalah uji kelayakan aplikasi kepada user.

\section{B. Hasil Uji Coba Kelayakan}

Hasil pengujian dan kelayakan yang digunakan dengan menggunakan jumlah responden adalah 31 orang yang terdiri dari pengguna yaitu siswa Sekolah Dasar. Jumlah pernyataan sebanyak lima pernyataan yang dimana masing-masing pernyataan bersangkutan dengan tujuan dan rumusan masalah.

1. Tampilan Aplikasi augmented reality alat peraga pengenalan hewan purbakala sudah menarik. Dari hasil persentase, responden yang menyatakan sangat setuju sebanyak $74 \%$, setuju sebanyak 23\%, 3\% kurang setuju dan tidak setuju $0 \%$. Maka dapat disimpulkan bahwa tampilan aplikasi Augmented Reality Sebagai Alat Peraga Pengenalan Hewan-Hewan Purbakala Dengan Animasi 3D Menggunakan Metode Single Marker sudah menarik.

2. Bentuk 3D augmented reality alat peraga pengenalan hewan purbakala yang ditampilkan sudah sesuai dengan gambar marker dan dapat dijadikan sebagai alat peraga. Dari hasil persentase, responden yang menyatakan sangat setuju sebanyak $74 \%$, setuju sebanyak $26 \%, 0$ $\%$ kurang setuju dan tidak setuju $0 \%$. Maka dapat disimpulkan bahwa bentuk 3D aplikasi Augmented Reality sebagai alat peraga pengenalan hewan-hewan purbakala dengan animasi 3d menggunakan metode single marker sudah sesuai dengan gambar pada marker dan dapat dijadikan sebagai alat peraga.

3. IV.2.3 Suara atau audio dari masing-masing object 3D terdengar jelas. Dari hasil persentase, responden yang menyatakan sangat setuju sebanyak 65\%, setuju sebanyak 19\%, 13\% kurang setuju dan tidak setuju $3 \%$. Maka dapat disimpulkan bahwa suara atau audio dari masing-masing objek aplikasi Augmented Reality sebagai alat peraga pengenalan hewanHewan Purbakala Dengan Animasi 3D menggunakan metode single marker sudah terdengar cukup jelas.

4. Informasi yang ditampilkan pada tiap-tiap binatang pada aplikasi sudah jelas. Dari hasil persentase, responden yang menyatakan sangat setuju sebanyak 55\%, setuju sebanyak $26 \%$, $10 \%$ kurang setuju dan tidak setuju $10 \%$. Maka dapat disimpulkan bahwa suara atau audio dari masing-masing objek aplikasi Augmented Reality Sebagai Alat Peraga Pengenalan hewan-hewan purbakala dengan animasi 3d menggunakan metode single marker sudah terdengar cukup jelas.

5. Aplikasi augmented reality alat peraga pengenalan hewan purba menambah minat belajar untuk lebih dalam mengenal hewan hewan Purbakala. Dari hasil persentase, responden yang menyatakan sangat setuju sebanyak 52\%, setuju sebanyak 32\%, $10 \%$ kurang setuju dan tidak setuju $6 \%$. Maka dapat disimpulkan Aplikasi ini dapat menambah minat belajar Responden.

\section{PENUTUP}

\section{A. Kesimpulan}

Kesimpulan dari penelitian ini adalah .

1. Aplikasi "Augmented Reality Sebagai Alat Peraga Pengenalan Hewan-Hewan Purbakala Dengan Animasi 3D Menggunakan Metode Single Marker" dapat menampilkan animasi 3D dari hewan purba jenis dinosaurus. 
2. Aplikasi "Augmented Reality Sebagai Alat Peraga Pengenalan Hewan-Hewan Purbakala Dengan Animasi 3D Menggunakan Metode Single Marker".

3. Aplikasi "Augmented Reality Sebagai Alat Peraga Pengenalan Hewan-Hewan Purbakala Dengan Animasi 3D Menggunakan Metode Single Marker" dapat menjadi sebuah alat peraga.

4. Aplikasi ini dapat diinstall pada versi android Gingerbread (2.3), dengan processor minimum armv7.

\section{B. Saran}

Saran untuk penelitian ini adalah .

1. Pembuatan marker harus menggunakan warna yang banyak dan cerah agar mudah untuk dibaca oleh sensor kamera.

2. Kamera smartphone yang digunakan harus memiliki fitur auto fokus.

3. Untuk mengeluarkan suara pengguna harus menekan virtual button atau menutup logo android pada halaman marker.

4. Format 3D animasi yang digunakan untuk Augmented reality ini menggunakan format .fbx.

5. Format suara yang digunakan menggunakan format .mp3 dan suara yang terdengar juga harus jelas agar mudah untuk didengar.

\section{DAFTAR PUSTAKA}

[1] Nugraha,Iwan setya., Kodrat imam satoto dan Kurniawan teguh martono. 2013. Makalah Seminar Tugas Akhir: Pemanfaatan Augmented Reality Untuk Pembelajaran Pengenalan Alatmusik Piano. Program
Studi Sistem Komputer. Fakultas Teknik, Universitas Diponegoro

[2] Palmer, D. .2002. Buku saku Fosil. Penerjemah: Yulin Lestari. Jakarta: Erlangga.

[3] Badudu, J.S. dan S.M. Zein. 2001. Kamus Umum Bahasa Indonesia. Pustaka Sinar Harapan. Jakarta.

[4] Yudhastara,Bryan. 2012. Teknologi Augmented Reality Untuk Buku Pembelajaran Hewan Pada Anak Usia Ini Secara Virtual.STIMIK AMIKOM Yogyakarta

[5] Roedavan .Rickman. 2014. Unity Tutorial Game engine.Yogyakarta.

[6] Soraya,Maria dan Sal Divita. 2012. T-rex dan 11 Dinosaurus Yang Perlu Kamu Ketahui.

[7] Hidayat, Yoni Wibowo, Hestiasari Rante, Achmad Subhan KH.2011. Implementasi Teknik Sound Effect Dan Voice Over Dalam Pembuatan Video Dokumenter Perlindungan Anak Di Kawasan Dolly. Prodi Multimedia Broadcasting, Jurusan Telekomunikasi. Politeknik Elektronika Negeri Surabaya.

[8] Djalle, Zaharuddin G. The Making of 3D Animation Movie. Jakarta: informatika, 2009

[9] Aditya. 2009. Trik Dahsyat menjadi Animator 3D Andal. Yogyakarta:Andi Offset.

[10] Bonafix, Dominicus Nunnun. 2005. Animasi 3D profesional dengan maya. Jakarta: Elex Media Komputido.

[11] Borg, James.2013. "Buku pintar memahami kode bahasa tubuh". Diva press, februari

[12] Prakosa, gatot.2010. Pengetahuan dasar film animasi indonesia, Jakarta: FFTV-IKJ.

[13] Gustianto,Robie, dan Ricoh polda nababan.2014. Media Pembelajaran Interaktif Pengenalan Hewan Purba Menggunakan Metode Augmented Reality Berbasis Android.Batam.Politeknik Negeri Batam

[14] Ari Listiyani, Dwi. 2009. Sejarah untuk kelas X, Jakarta. Pusat Perbukuan Departemen Pendidikan Nasional 